\title{
On the Adsorption of Aspartate Derivatives to Calcite Surfaces in Aqueous Environment
}

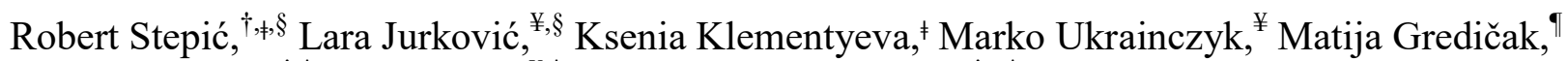
David M. Smith, ${ }^{\dagger, *}$ Damir Kralj, ${ }^{\ddagger}, *$ and Ana-Sunčana Smith ${ }^{\dagger, *}, *$

${ }^{\dagger}$ Group for Computational Life Sciences, Division of Physical Chemistry, Ruđer Bošković Institute (RBI), Bijenička cesta 54, 10000 Zagreb, Croatia

${ }^{\ddagger}$ PULS Group, Institute for Theoretical Physics and Interdisciplinary Center for Nanostructured Films, FAU Erlangen-Nürnberg, Cauerstrasse 3, 91058 Erlangen, Germany

${ }^{¥}$ Laboratory for Precipitation Processes, Division of Material Chemistry, RBI, Bijenička cesta 54, 10000 Zagreb, Croatia

" Laboratory for Biomimetic Chemistry, Division of Organic Chemistry and Biochemistry, RBI, Bijenička cesta 54, 10000 Zagreb, Croatia

$\S$ These authors contributed equally

\section{Supporting Information}

\section{Contents}

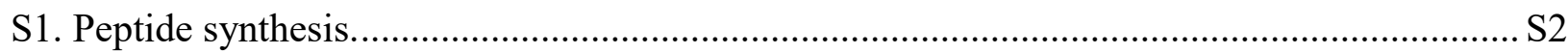

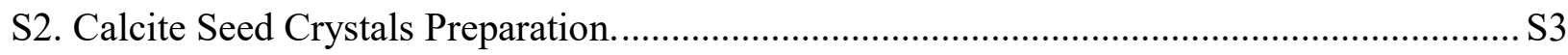

S3. Calcite crystal growth kinetics in the presence of additives........................................... S3

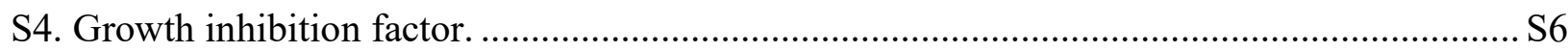

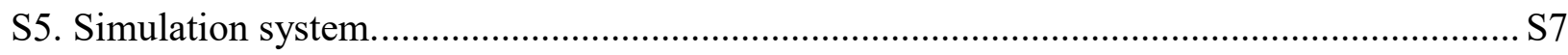

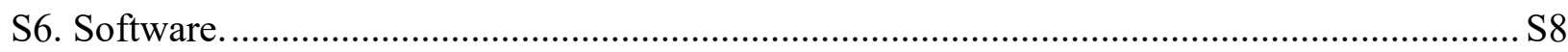

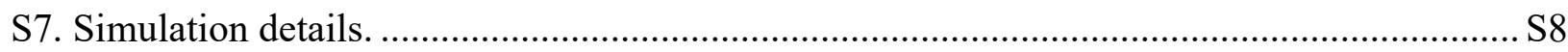

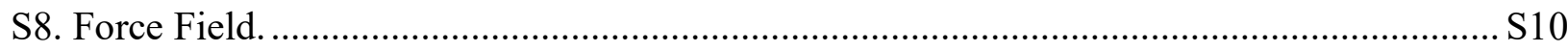

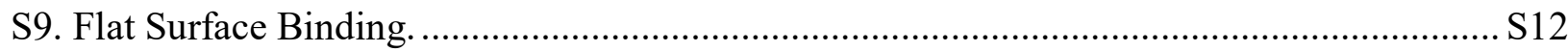

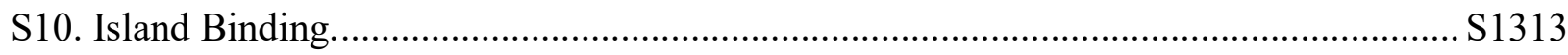

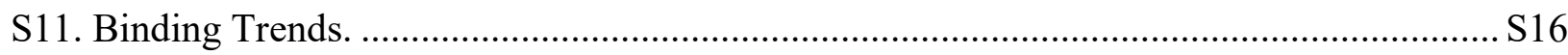

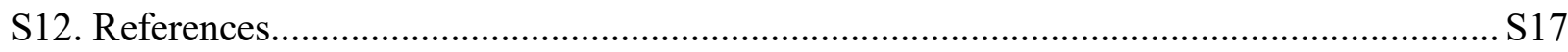


S1. Peptide synthesis. (L-Asp) $)_{3}$ was synthesized according to the following procedure: BocAsp(OMe)-OH (1 eq) and $N$-hydroxysuccinimide (1.1 eq) were dissolved in dimethyl formamide (DMF) and placed in an ice bath. $N, N^{\prime}$-dicyclohexylcarbodiimide (1.2 eq) was dissolved in DMF and added dropwise into the initial solution. The reaction mixture was stirred for $30 \mathrm{~min}$ at $0{ }^{\circ} \mathrm{C}$, and then at room temperature overnight. The solution was filtered, and the mother liquor was added dropwise into the suspension of $\mathrm{H}-\mathrm{Asp}(\mathrm{OMe})-\mathrm{OH}(1.1 \mathrm{eq})$ and $\mathrm{KHCO}_{3}(1.1 \mathrm{eq})$ in water, and stirred at room temperature for $2 \mathrm{~h}$. The reaction mixture was filtered and the filtrate was acidified with citric acid to $\mathrm{pH}=2$. The product was extracted with ethyl acetate, washed with saturated $\mathrm{NaCl}$ solution and water, and purified by column chromatography (eluens: ethyl acetate-petrol-acetic acid 5:5:0.5) to give Boc-Asp(OMe)-Asp(OMe)-OH. Isolated dipeptide was re-submitted to the procedure described above to give tripeptide Boc-Asp(OMe)-Asp(OMe)Asp(OMe)-OH. Boc and ester deprotection was achieved by treating the tripeptide first with $1 \mathrm{M}$ $\mathrm{NaOH}$, and then with TFA/ $\mathrm{H}_{2} \mathrm{O}$ 9:1. Resulting product was dissolved in methanol and triturated with diisopropylether. Precipitate was filtered, and desalted using a C18 matrix to give (L-Asp) 3 in $11 \%$ overall isolated yield (over 3 steps). Structural data (NMR shifts, physical and chemical constants) of prepared tripeptide are in accordance with commercially available compound.

Distribution of ionic species - In order to be able to interpret the data we investigate the contributions of various ionic species (Scheme S1), we carefully considered the various protonation states of the amino acids. Notably, the precipitation experiments were performed in a relatively narrow, approximately neutral, $\mathrm{pH}$ range. This is most easily seen in Figures 1 and $\mathrm{S} 1$, where the precipitation starts at around $\mathrm{pH}=8.0$ and ends at around $\mathrm{pH}=7.2$

In this experimental range, it is clear that the dominant form of Asp during a typical precipitation experiment is the mononegative zwitterion (between 97.5 and $98.9 \%$ ). Importantly, at this $\mathrm{pH}$, the terminal groups are expected to be $\mathrm{NH}_{3}{ }^{+}$. Neutral $\mathrm{NH}_{2}$ groups (in solution) would not be expected to dominate until $\mathrm{pH}$ values above 10 , which corresponds to the dinegative anionic form. $\mathrm{NH}_{2}$ groups could, however, also occur in tautomeric equilibria within any of the different net protonation states, an example of which is shown for the mononegative zwitterion on the right side of Scheme S1. However, in solution, these equilibria are strongly dominated by the zwitterionic forms. Overall, in solution, at $\mathrm{pH}$ values relevant for the precipitation equilibria, Asp, and its derivatives are expected to be dominated by the mononegative zwitterion. 


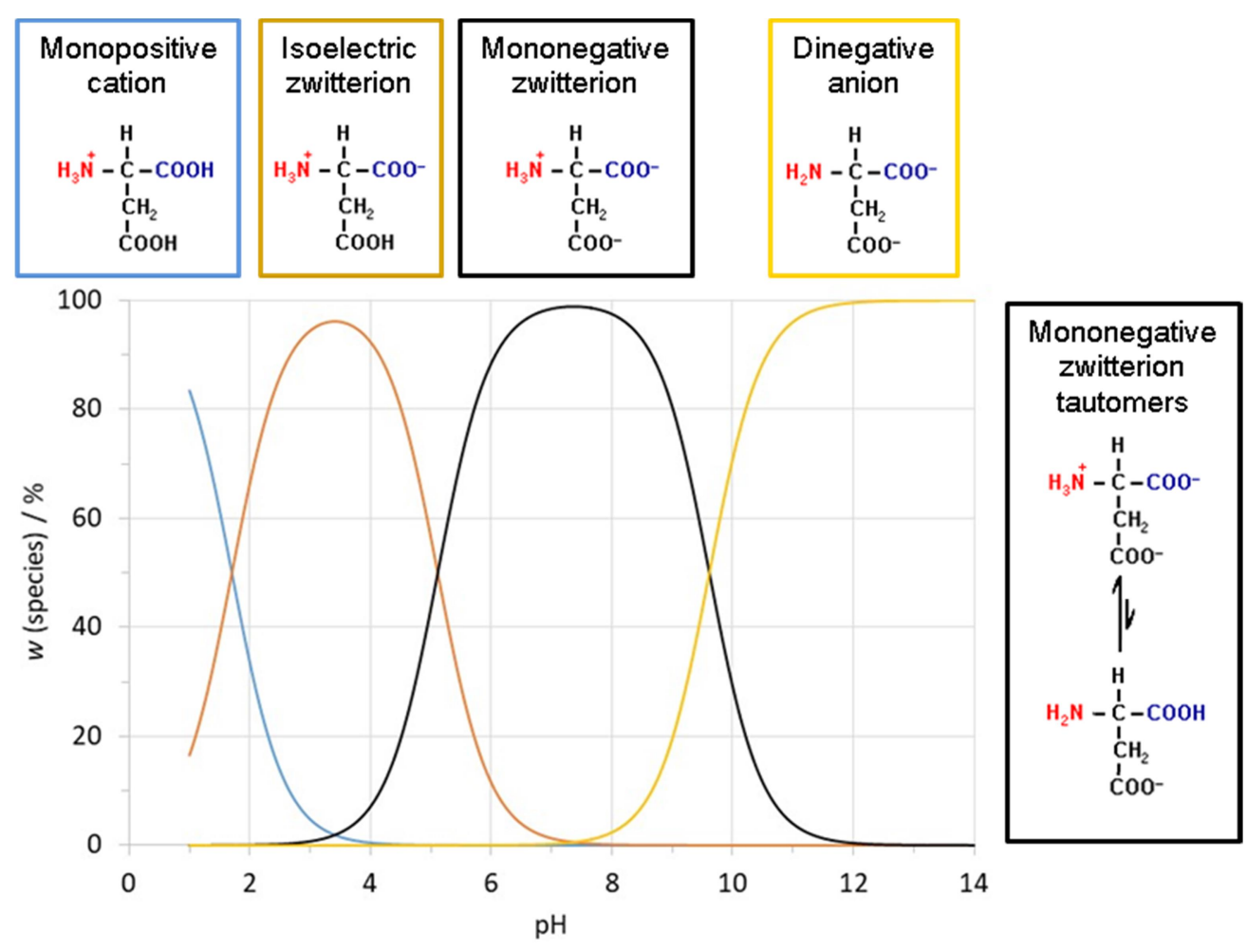

Scheme S1: Distribution of ionic species of the Aspartic acid as a function of $p H$. These distributions were calculated using the relevant protolytic equilibria and equilibrium constants, following the refs. [16] and [17] of the manuscript.

S2. Calcite Seed Crystals Preparation. Relatively large amount of structurally and morphologically well-defined rhombohedral calcite seed was prepared by previously described semi-continuous carbonation method in the $\mathrm{Ca}(\mathrm{OH})_{2}(\mathrm{~s})-\mathrm{H}_{2} \mathrm{O}(\mathrm{l})-\mathrm{CO}_{2}(\mathrm{~g})$ system ${ }^{1}$. Specifically, calcite seed has been prepared at constant concentration of dissolved calcium ions, $c_{\text {tot }}=2.0$ mmol dm $\mathrm{dm}^{-3}$, by controlling the addition of $\mathrm{Ca}(\mathrm{OH})_{2}$ suspension $\left(c\left(\mathrm{Ca}(\mathrm{OH})_{2}\right)=100 \mathrm{~g} \mathrm{dm}^{-3}\right)$ into the thermostated bench-scale glass reactor, $V=6.0 \mathrm{dm}^{3}$. The mineralogical composition of the dried seed samples was analysed by FT-IR spectroscopy and by X-ray powder diffraction (Rigaku Ultima IV diffractometer, $\mathrm{Cu} \mathrm{K} \alpha$ radiation, Ni filter, $5^{\circ}$ Soller slits and proportional counter in Bragg- Brentano parafocusing geometry). The morphology of the crystals was observed by scanning electron microscopy (SEM, JEOL GSM-7000F instrument). For the SEM observations, the dried samples were attached by carbon tape to an aluminium stub. The specific surface area was determined by the multiple BET method (Micromeritics, Gemini), using liquid nitrogen.

S3. Calcite crystal growth kinetics in the presence of additives. The calcite crystal growth kinetic experiments were performed in a thermostated double-walled glass vessel $\left(400 \mathrm{~cm}^{3}\right)$. The 
metastable calcium carbonate solutions were prepared by mixing the equal volumes of $\mathrm{CaCl}_{2}$ and $\mathrm{NaHCO}_{3}$ solutions $\left(\mathrm{c}=5.0 \mathrm{mmol} \mathrm{dm}{ }^{-3}, \mathrm{pH}_{\mathrm{i}} \approx 8.0\right)$. The initial supersaturation of metastable solution was low, $\mathrm{S} \approx 3.5 ; \mathrm{S}=\left[\left(\mathrm{a}\left(\mathrm{Ca}^{2+}\right) \mathrm{a}\left(\mathrm{CO}_{3}{ }^{2-}\right)\right) / \mathrm{K}_{\mathrm{sp}}\right] 1 / 2$. An appropriate amount of the selected biomolecule ( $\mathrm{L}-\mathrm{Asp},(\mathrm{L}-\mathrm{Asp})_{2}$ or $\left.(\mathrm{L}-\mathrm{Asp})_{3}\right)$ was added into the bicarbonate solution before the mixing. The range of concentrations of biomolecules which caused the observable effects in the precipitation systems were initially determined and applied: the L-Asp varied in the range, 1.0 mmol dm ${ }^{-3}<\mathrm{c}(\mathrm{L}-\mathrm{Asp})<25.0 \mathrm{mmol} \mathrm{dm}^{-3}$, the $(\mathrm{L}-\mathrm{Asp})_{2}$ concentration was lower, $10.0 \mu \mathrm{mol} \mathrm{dm}^{-}$ ${ }^{3}<\mathrm{c}(\mathrm{L}-\mathrm{Asp})_{2}<250.0 \mu \mathrm{mol} \mathrm{dm}{ }^{-3}$, as well as the concentration of $(\mathrm{L}-\mathrm{Asp})_{3}, 0.5 \mu \mathrm{mol} \mathrm{dm}{ }^{-3}<\mathrm{c}(\mathrm{L}-$ Asp) $)_{3}<10.0 \mu \mathrm{mol} \mathrm{dm}{ }^{-3}$.

$\mathrm{T}$ he experiments were started by introducing $35.0 \mathrm{mg}$ of previously prepared rhombohedral calcite seed crystals in the system $\left(A=0.55 \mathrm{~m}^{2} \mathrm{dm}^{-3}\right)$, immediately after mixing of the reactant solutions. The experiments were carried out at $25^{\circ} \mathrm{C}$ and the systems were continuously stirred at a constant rate by means of a Teflon-coated magnetic stirring bar. The crystal growth process was followed by measuring the $\mathrm{pH}$ of the solution, using a combined glass-calomel electrode (Red Rod) and PHM 290, Radiometer (Figure S1). Samples of the suspension were periodically taken from the system in order to determine the total concentration of dissolved calcium by ion chromatography (ICS-1100, Dionex) and also to characterize the solid phase composition (ATR FT-IR, Tensor II, Bruker spectrophotometer). The chemicals used to prepare the reactant solutions, $\mathrm{CaCl}_{2}, \mathrm{NaHCO}_{3}, \mathrm{NaOH}, \mathrm{HCl}, \mathrm{L}-\mathrm{Asp}$ and (L -Asp) $)_{2}$, were analytical grade and the
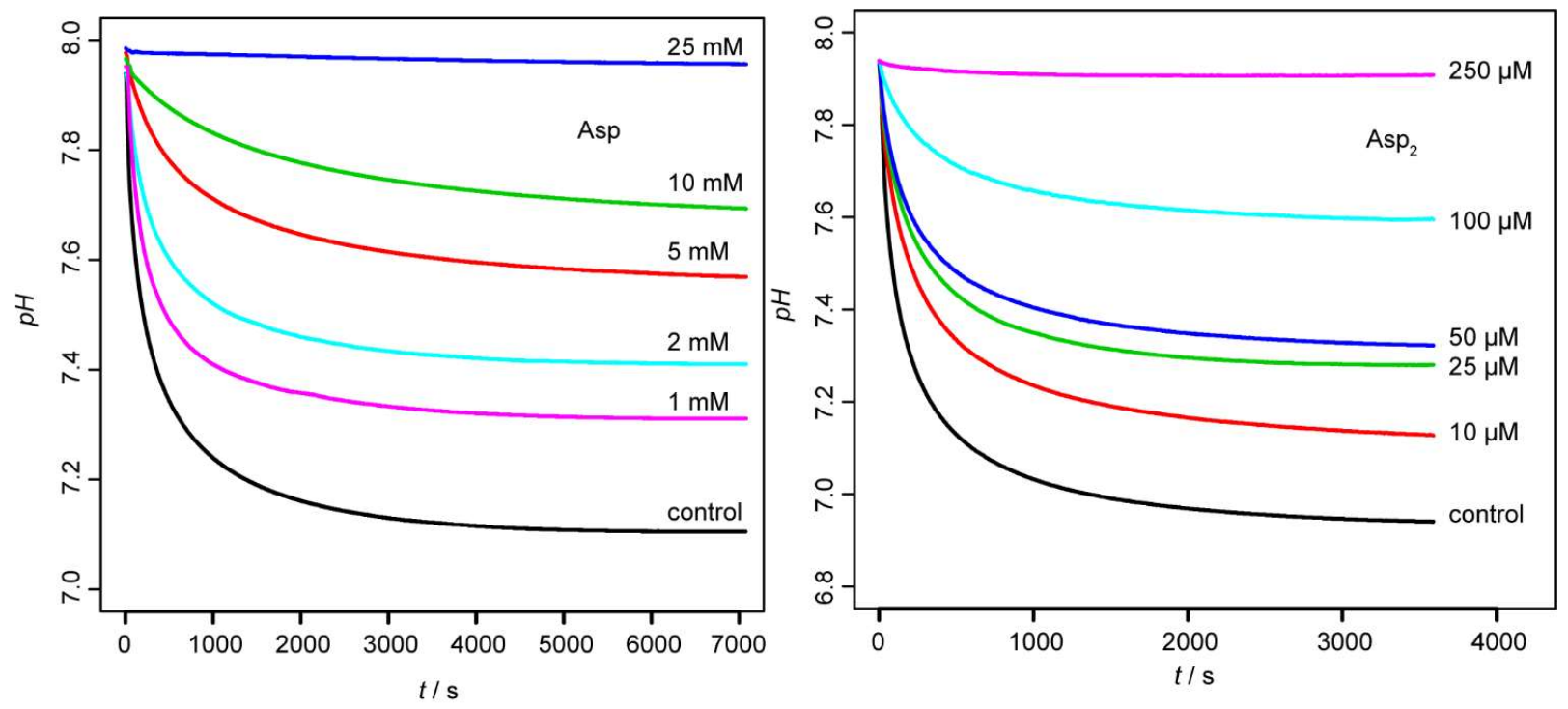

Figure S1. Variation of $\mathrm{pH}$ with different concentrations of Asp (top) and Asp 2 (bottom). 
deionized water was of high quality (conductivity $<0.055 \mu \mathrm{S} \mathrm{cm}^{-1}$ ), while the (L -Asp) $)_{3}$ was synthesized by the protocol described previously.

Calculations of the solution composition (molar concentrations and activities of relevant ionic species), at any moment in the calcite crystal growth process, were based on continuous $\mathrm{pH}$ measurements and the known initial total concentrations of the reactants. The detailed calculation procedure, which takes into account the respective protolytic equilibria and equilibrium constants, as well as the charge and mass balance equations, is described
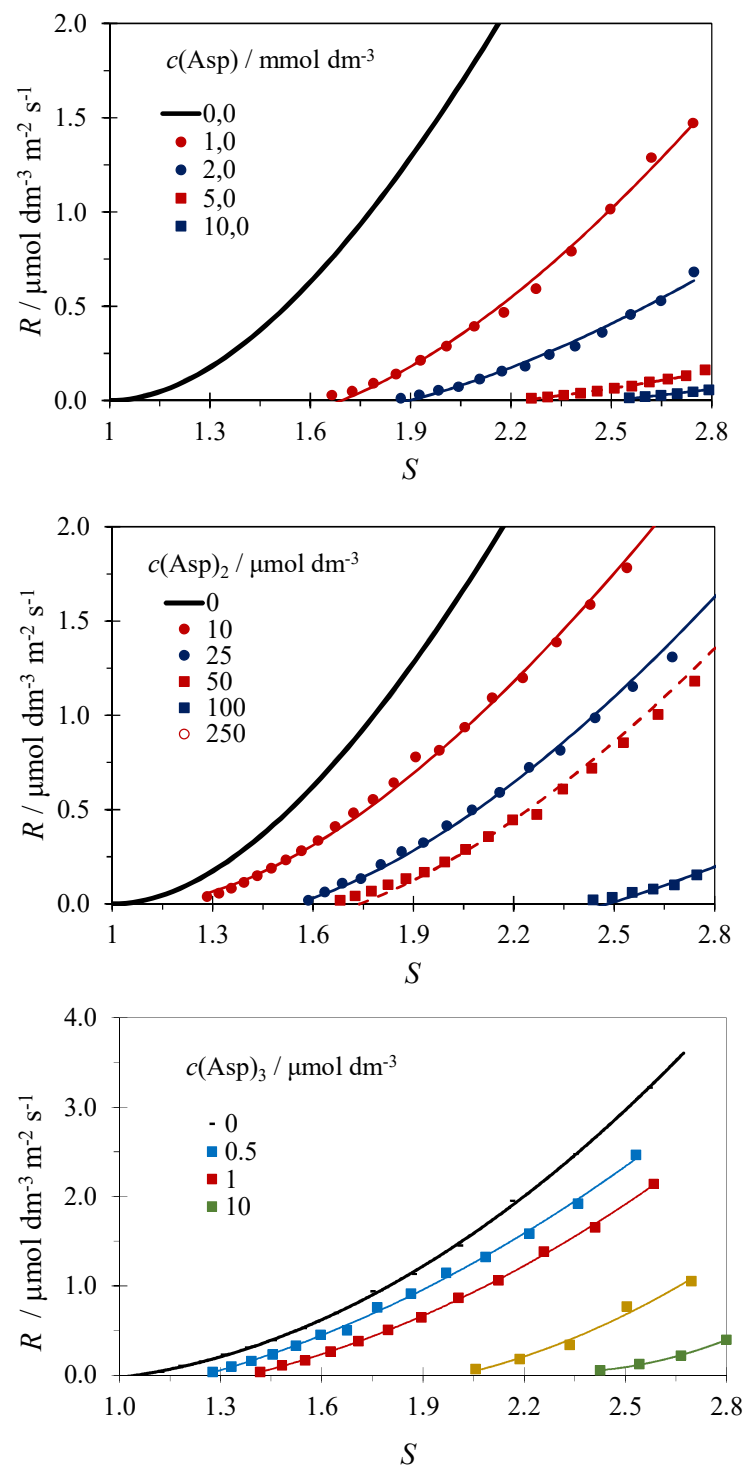

Figure S2. Crystal growth rate of calcite as a function of relative supersaturation in the systems containing different concentrations of additives. The lines are consistent with a rate law of the form: $R=k_{s}(S-1) \cdot \ln S$. The curves corresponding to the additive-free systems are shown as solid bold lines. 
previously. ${ }^{2,3}$ The formation of respective ionic species of the used biomolecule has been considered. The crystal growth rate, $R$, was calculated by numerical differentiation of the total dissolved calcium concentration, $C a_{\text {tot }}$, as a function of time $t$, and normalized with respect to the surface area of the precipitate, $A$, at a particular moment: $R=-\mathrm{d} C a_{\mathrm{tot}} /(\mathrm{d} t \cdot A)$. During the growth of calcite crystals, the total surface area increases, which was also considered in calculations and was calculated by using the data on the concentration of precipitated total calcium carbonate.

Figure S2 shows the growth rates obtained for model systems and for the systems containing different additives, plotted as a function of relative supersaturation. It is evident from the values of critical supersaturation, $\mathrm{S}^{*}$, obtained for comparable additive concentrations, that the inhibition efficiency is significantly different: (Asp $)_{3}>>(\text { Asp })_{2}>>$ Asp. The controlling growth mechanism of calcite in the model system, but also in the system containing additive, have been determined by testing the appropriate crystal growth models. As could be expected for the lowsupersaturated systems, the growth on the spiral dislocation, described by the rate law, $R=k_{\mathrm{s}}(S$ 1) $\ln S$, has been observed and the appropriate value of the rate constant, $k_{\mathrm{s}}=2.0 \pm 0.02 \mu \mathrm{mol} \mathrm{dm}^{-}$ ${ }^{3} \mathrm{~m}^{-2} \mathrm{~s}^{-1}$, was found. The results are consistent with values obtained for calcite growth at similar experimental conditions. ${ }^{1,2}$

S4. Growth inhibition factor. The decreased of the growth inhibition factor with increasing supersaturation (Figure S3) is consistent with the model which correlates the size of the critical surface nucleus and the separation of the active sites at the crystal surfaces available for impurity adsorption.
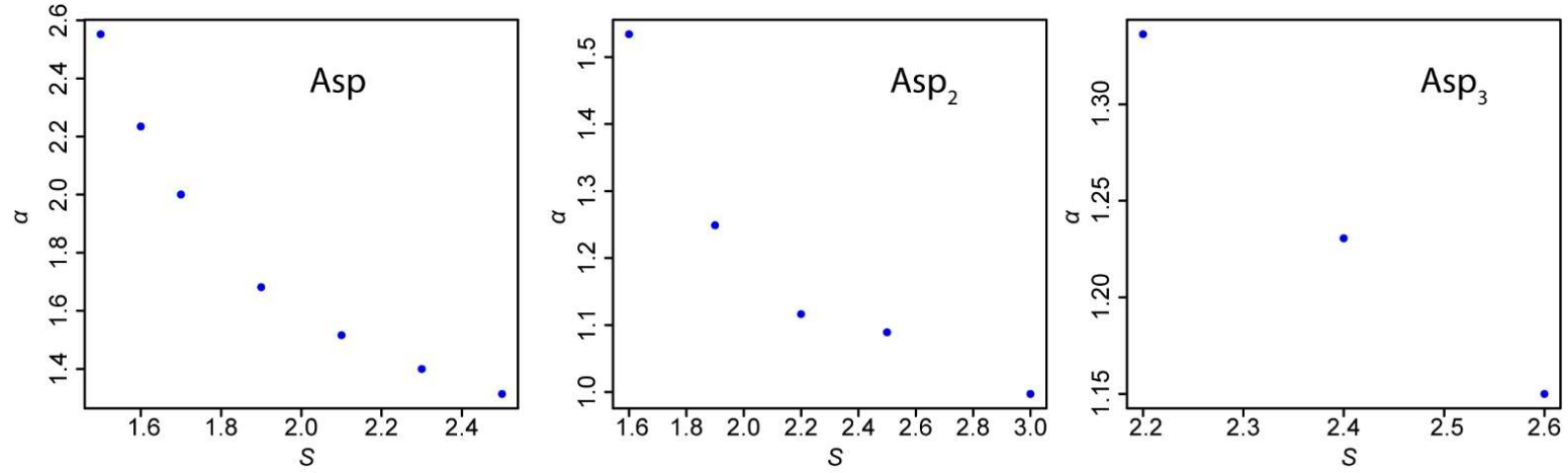

Figure S3. Growth inhibition factor, $\alpha$, as a function of supersaturation for different biomolecular additives. 


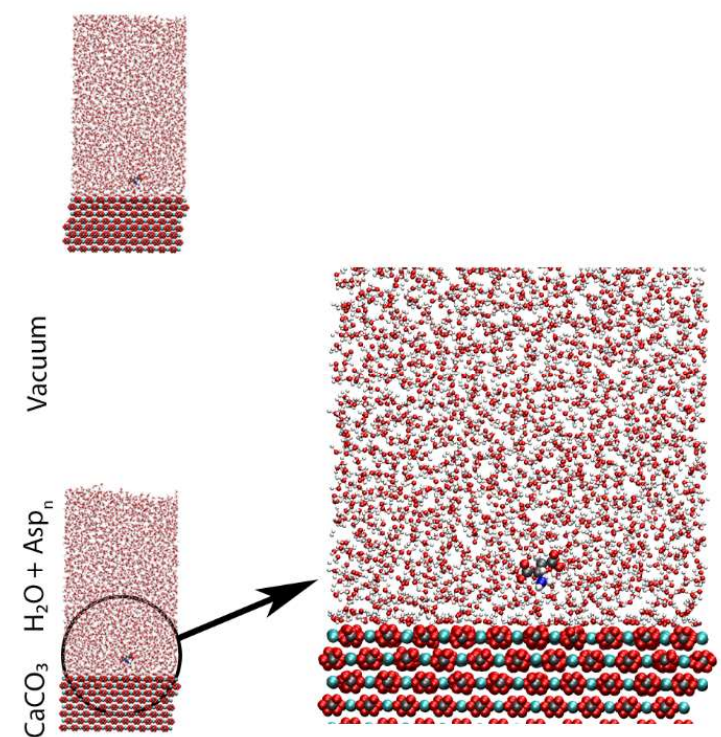

(a)

(b)

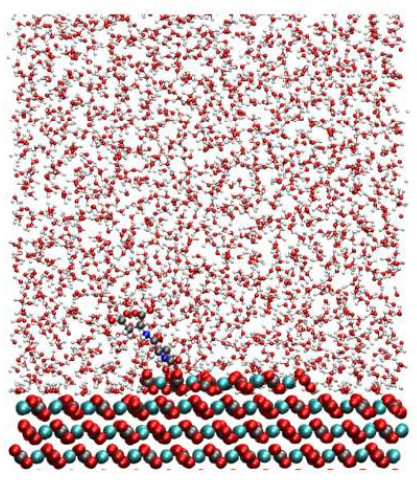

(c)

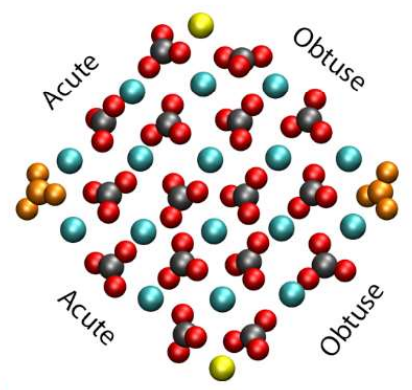

(d)

Figure S4. Description of the system. (a) Whole system setup containing calcite slab at the bottom, water solvated biomolecule layer in the middle and a vacuum layer on top. Periodic image is also shown to illustrate the total vertical size of the system. (b) Close-up of the system built with a flat (104) surface of calcite. (c) Snapshot of the system which contains an island on top of the (104) surface. (d) Top-down view of the island showing structural details where acute and obtuse edges are marked. Calcium corners are shown in yellow, and obtuse and acute carbonate corners are shown in orange.

S5. Simulation system. The calcite slab employed is approximately $2.2 \mathrm{~nm}$ thick. The corresponding surface area is $4.7 \times 4.7 \mathrm{~nm}^{2}$ and the slab contains 960 calcium carbonate units. The island is constructed following the procedure already reported in previous work, ${ }^{4}$ where 16 calcium carbonate pairs were cut from the bottom layer and put on the topmost layer forming a rhombus shaped island with 5 distinct features. The features of the island are a calcium corner, acute carbonate corner, acute carbonate edge, obtuse carbonate corner, and obtuse carbonate edge. Above the calcite surface we have placed a $7.7 \mathrm{~nm}$ layer containing 6000 water molecules, which reproduces the ambient water density in bulk. On top of the water, we have included an 11 $\mathrm{nm}$ thick vacuum, to prevent strong ordering of water in the upper layer induced by the bottom surface of the calcite slab. For balanced results, it is essential to construct a water layer thick 
enough that at some point it reproduces bulk properties, non-perturbed by the presence of the two enclosing interfaces.

The (poly) amino acids in our study are immersed into the water completing the spatial description. Motivated by our analysis in the section S1, the side-chain carboxylate groups were used in the ionized $\left(\mathrm{CO}_{2}{ }^{-}\right)$forms, as were the $\mathrm{N}$ - and C-terminal ends $\left(\mathrm{H}_{3} \mathrm{~N}^{+}\right.$- and $\left.-\mathrm{CO}_{2}{ }^{-}\right)$of each Asp-derivative, in accordance to expectations at neutral $\mathrm{pH}$ (Scheme 1 of the manuscript). Naturally, the simulations were performed with a constant $\mathrm{pH}$ of 7 , as is a common practice in the field. An illustration of the system described above is shown in Figure S4.

S6. Software. All the molecular dynamics simulations were performed using GROMACS 4.5.5. ${ }^{5}$ Quantum mechanical optimizations were done in Gaussian09. ${ }^{6}$ RESP fitting of charges and Amber parameter extraction was carried out with AmberTools 2016. ${ }^{7}$ Optimization of the crystal structures and parameter fitting was done using the General Utility Lattice Program (GULP). ${ }^{8}$ For visualization and analysis of produce trajectories we used Visual Molecular Dynamics (VMD). ${ }^{9}$

S7. Simulation details. Fully atomistic molecular dynamics simulations were performed. We work in the canonical ensemble, keeping the number of particles, volume and the temperature $(300 \mathrm{~K})$ constant. Temperature control was exerted through stochastic dynamics with the coupling time-constant of $0.1 \mathrm{ps}$. Long-range interactions were resolved using the particle mesh Ewald $^{10,11}$ approach where the cutoff of $1.2 \mathrm{~nm}$ was used in the direct space sum. Short range non-bonding interactions were calculated using a cutoff of $1.2 \mathrm{~nm}$. In the simulations, noninteracting layers at the bottom of the calcite slab were kept frozen to reproduce the bulk properties of the crystal better. Bonds with hydrogen were constrained using the LINCS algorithm. Prepared systems were minimized using the steepest descent method and then equilibrated for 200 ps.

The relevant biomolecule was pulled to the surface, equilibrated there for $20 \mathrm{ps,} \mathrm{and} \mathrm{then}$ pulled away from the surface along the z-direction, perpendicular to the surface. During the pulling, the COM of the amino acid was attached to a moving virtual particle. The spring constant of the attachment was $1000 \mathrm{~kJ} \mathrm{~mol}^{-1} \mathrm{~nm}^{-2}$ and the rate of movement of the virtual particle was $0.01 \mathrm{~nm} / \mathrm{ns}$. From the $400 \mathrm{ps}$ long pull trajectory, 21 system configurations were extracted. Each of those configurations had a different distance between the COM of the amino acid and the COM of the frozen part of the calcite slab. There were 16 equidistant configurations 


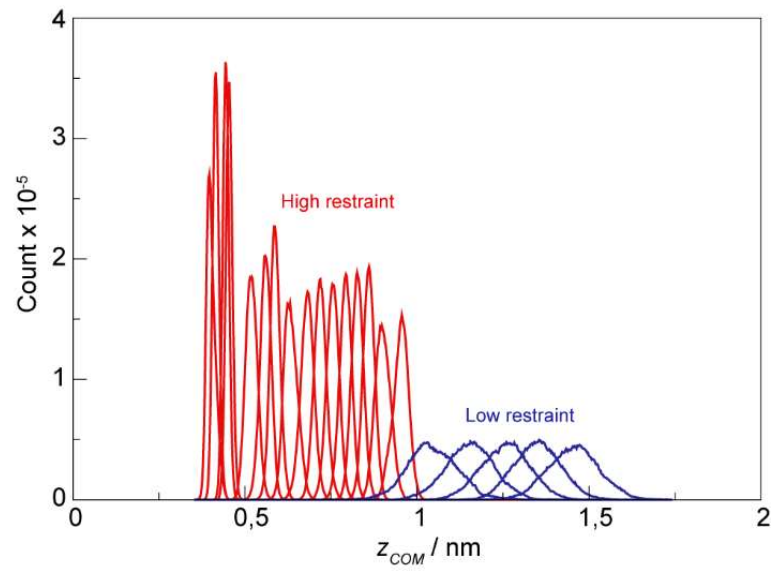

Figure S5. A set of histograms from a single umbrella sampling simulation. Closer to the surface higher restraint was applied to the center of mass of biomolecule (red), while for biomolecule further away from the surface lower restraint was used (blue).

for the biomolecule residing in the vicinity of the surface characterized by increasing the separation by $0.04 \mathrm{~nm}$ between COMs for each successive configuration, and 5 configurations where the biomolecule was further away from the surface for which the separation between COMs increased by $0.1 \mathrm{~nm}$. Those configurations were starting points for umbrella sampling simulations using harmonic bias potentials. The overall protocol thus ensures sufficient sampling of a geometric region extending up to $1.2 \mathrm{~nm}$ from the surface. This allowed for construction of free energy profiles with a well-defined water bulk in which the organic molecule no longer interacts with the inorganic surface.

In the biased sampling simulations, the force constant was set to $500 \mathrm{~kJ} \mathrm{~mol}^{-1} \mathrm{~nm}^{-2}$ for all configurations where the biomolecule is further away from the surface and a value of $7000 \mathrm{~kJ}$ $\mathrm{mol}^{-1} \mathrm{~nm}^{-2}$ was used close to the surface. All the sampling configurations were propagated for 8 ns. For analysis purposes, the data from the first ns was omitted. This resulted in the distributions of the positions of COM of the biomolecule that were collected into separate histograms for each window. An example of such a collection of histograms is shown in Figure S5. If we add up the simulation time over 21 windows, we obtain a total of 147 ns of sampling time for each umbrella simulation. To obtain unbiased distribution and potentials of mean force (PMF) from the histograms, we used the weighted histogram analysis method (WHAM). ${ }^{12}$ Convergence for all obtained distributions was checked by calculating PMFs for the first 5, 6 and 7 ns. Island sampling required significantly larger amount of data, as each feature needs to be sampled separately. To improve statistics, we added an additional run which starts in the middle of the island. Each individual run produced $147 \mathrm{~ns}$ of data, which amounted to $882 \mathrm{~ns}$ of data per biomolecule. 


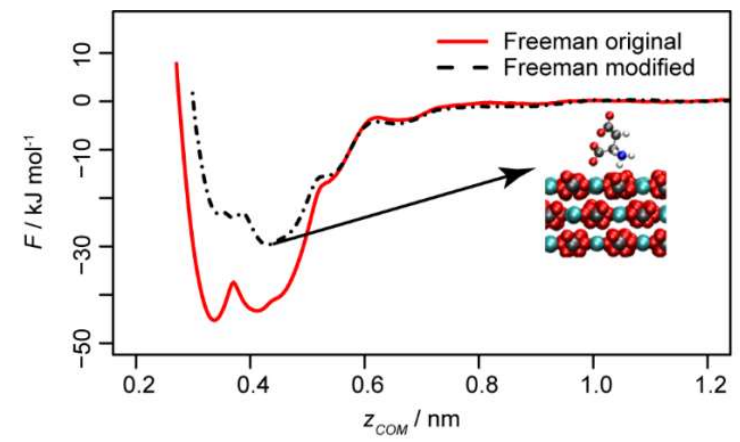

Figure S6. Potential of mean force for the process of binding of aspartate to the flat (104) surface of calcite. Effect of the proposed modification of the Freeman method on the PMF with Raiteri calcite force field.

S8. Force Field. Calcite charges and non-bonding parameters for the potential of the Buckingham type, as well as the bonding parameters, were taken from work by Raiteri. ${ }^{13-14}$ Raiteri et al. calcite force field was constructed with a focus on reproducing the free energies of solvation of calcium and carbonate ions, and consequently much more attention was devoted to having a proper description of the interface with water. Since our goal is to provide calculations of thermodynamic potentials, such as the Helmholtz free energies of binding, it is crucial to have a consistent description of the crystal-water interface to account for the entropic contribution of displacement of water to the free energies as precisely as possible. The water model used is TIP3P. ${ }^{15}$ Biomolecular parameters for intramolecular interactions and interactions with water were taken from Amber ff99sb-ILDN ${ }^{16}$ force field (Lennard-Jones type). The expression that we utilized for this interaction between atoms $\mathrm{i}$ and $\mathrm{j}$ is given by the following equation:

$$
E_{i j}=\frac{A_{i j}}{r^{12}}+\frac{B_{i j}}{r^{6}}
$$

Parameters for interactions between the biomolecule and the calcium were obtained using an approach originally developed and used for zeolites by Schroeder et al. ${ }^{17}$, while the interactions with carbonates were taken from Amber ff99sb-ILDN following a slightly modified approach proposed by Freeman et al. ${ }^{18}$. The difference from methodology proposed by Freeman is that also crystal oxygen-biomolecule interaction is extracted from Amber, rather than employing combination rules. The parameters obtained in this way for Asp, $A_{s p}$ and $A_{s p}$ are shown in Tables S1-S3. The effect of using this kind of cross interaction instead of the standard Freeman methodology is showcased on the case of aspartate in Figure S6. We were using potentials of Buckingham and Lennard-Jones type simultaneously, avoiding the need to do additional fitting. Parameters for the interaction of water with the surface were taken from the article introducing the inorganic force field. ${ }^{14}$ Point charges for zwitterionic aspartate derivatives, which are not 


\begin{tabular}{|l|l|r|r|}
\hline Crystal & Biomolecule & $\mathbf{B} / \mathbf{~ k J ~ m o l}^{-\mathbf{1}} \mathbf{n m}^{\mathbf{6}}$ & $\mathbf{A} / \mathbf{~ k J ~ m o l}^{\mathbf{- 1}} \mathbf{~ n m}$ \\
\hline Oc & N3 & $2.83349 \mathrm{E}-03$ & $2.53897 \mathrm{E}-06$ \\
\hline Oc & H & $6.42266 \mathrm{E}-05$ & $4.29258 \mathrm{E}-09$ \\
\hline Oc & CT & $2.62220 \mathrm{E}-03$ & $2.71057 \mathrm{E}-06$ \\
\hline Oc & HP & $2.12946 \mathrm{E}-04$ & $4.71874 \mathrm{E}-08$ \\
\hline Oc & HC & $4.67792 \mathrm{E}-04$ & $2.27716 \mathrm{E}-07$ \\
\hline Oc & C & $2.32491 \mathrm{E}-03$ & $2.40326 \mathrm{E}-06$ \\
\hline Oc & O2 & $2.36347 \mathrm{E}-03$ & $1.58939 \mathrm{E}-06$ \\
\hline Oc & OP & $2.36347 \mathrm{E}-03$ & $1.58939 \mathrm{E}-06$ \\
\hline
\end{tabular}

Table S1. Interaction

parameters of oxygen from the crystal with every atom of Asp.

\begin{tabular}{|c|c|c|c|}
\hline Crystal & Biomolecule & $B / \mathrm{kJ} \mathrm{mol}^{-1} \mathrm{~nm}^{6}$ & 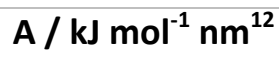 \\
\hline Oc & N3 & 2.83349E-03 & 2.53897E-06 \\
\hline Oc & $\mathrm{H}$ & $6.42266 \mathrm{E}-05$ & $4.29258 \mathrm{E}-09$ \\
\hline Oc & $\mathrm{CT}$ & $2.62220 \mathrm{E}-03$ & 2.71057E-06 \\
\hline Oc & $\mathrm{HP}$ & $2.12946 E-04$ & 4.71874E-08 \\
\hline Oc & $\mathrm{HC}$ & 4.67792E-04 & $2.27716 \mathrm{E}-07$ \\
\hline Oc & C6 & 2.32491E-03 & $2.40326 \mathrm{E}-06$ \\
\hline Oc & 0 & 2.36347E-03 & 1.58939E-06 \\
\hline Oc & $\mathrm{N}$ & 2.83349E-03 & 2.53897E-06 \\
\hline Oc & $\mathrm{H} 1$ & 3.85425E-04 & $1.54585 E-07$ \\
\hline Oc & C & 2.32491E-03 & $2.40326 \mathrm{E}-06$ \\
\hline Oc & $\mathrm{O} 2$ & 2.36347E-03 & 1.58939E-06 \\
\hline Oc & ON & 2.36347E-03 & 1.58939E-06 \\
\hline Oc & OK & 2.36347E-03 & 1.58939E-06 \\
\hline
\end{tabular}

Table S2. Interaction parameters of oxygen from the crystal with every atom of Asp ${ }_{2}$

\begin{tabular}{|l|l|r|r|}
\hline Crystal & Biomolecule & $\mathbf{B} / \mathbf{~ k J ~ m o l}^{-\mathbf{1}} \mathbf{n m}$ & $\mathbf{A} / \mathbf{~ k J ~ m o l}^{\mathbf{- 1}} \mathbf{n m}^{\mathbf{1 2}}$ \\
\hline Oc & N3 & $2.83349 \mathrm{E}-03$ & $2.53897 \mathrm{E}-06$ \\
\hline Oc & $\mathrm{H}$ & $6.42266 \mathrm{E}-05$ & $4.29258 \mathrm{E}-09$ \\
\hline Oc & CT & $2.62220 \mathrm{E}-03$ & $2.71057 \mathrm{E}-06$ \\
\hline Oc & HP & $2.12946 \mathrm{E}-04$ & $4.71874 \mathrm{E}-08$ \\
\hline Oc & HC & $4.67792 \mathrm{E}-04$ & $2.27716 \mathrm{E}-07$ \\
\hline Oc & C6 & $2.32491 \mathrm{E}-03$ & $2.40326 \mathrm{E}-06$ \\
\hline Oc & O & $2.36347 \mathrm{E}-03$ & $1.58939 \mathrm{E}-06$ \\
\hline Oc & N & $2.83349 \mathrm{E}-03$ & $2.53897 \mathrm{E}-06$ \\
\hline Oc & H1 & $3.85425 \mathrm{E}-04$ & $1.54585 \mathrm{E}-07$ \\
\hline Oc & $\mathrm{C}$ & $2.32491 \mathrm{E}-03$ & $2.40326 \mathrm{E}-06$ \\
\hline Oc & O2 & $2.36347 \mathrm{E}-03$ & $1.58939 \mathrm{E}-06$ \\
\hline Oc & ON & $2.36347 \mathrm{E}-03$ & $1.58939 \mathrm{E}-06$ \\
\hline Oc & OK & $2.36347 \mathrm{E}-03$ & $1.58939 \mathrm{E}-06$ \\
\hline Oc & OS & $2.36347 \mathrm{E}-03$ & $1.58939 \mathrm{E}-06$ \\
\hline
\end{tabular}

Table S3. Interaction parameters of oxygen from the crystal with every atom of $A_{s p}$ 


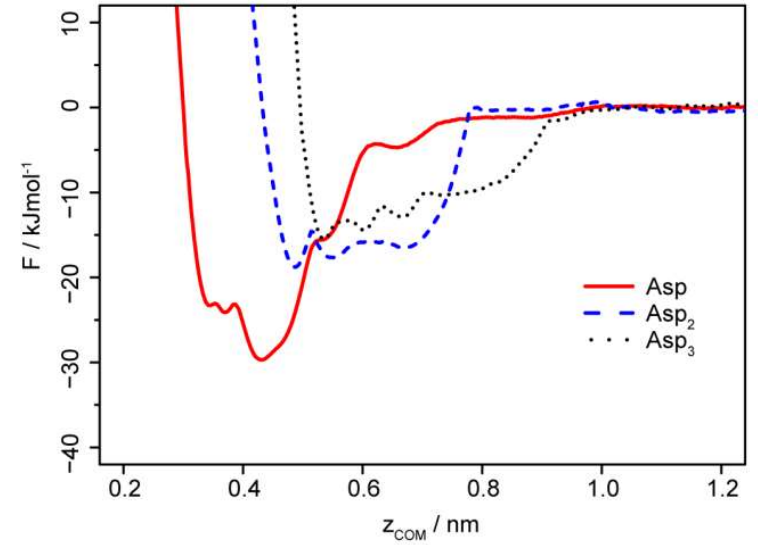

Figure S7. Potentials of mean force for Asp, Asp $_{2}$ and Asp $_{3}$ on the (104) surface of calcite showcasing a decreasing trend in binding energy with an increase in peptide chain length.

included in the used Amber variant, were obtained using the RESP fitting procedure after the optimization on MP2/6-31G(d) ${ }^{19}$ level and electrostatic potential calculation on HF/6-31G(d) level. The optimization was done in polarizable continuum $(\varepsilon=80)$ in order to screen strong Coulomb interactions and prevent the proton transfer that would otherwise occur in the zwitterion.

S9 . Flat Surface Binding. The obtained free energy profile (Figure S7) can be dissected to extract the atomistic details from the observed minima. Three different bound states are found for $\mathrm{Asp}, \mathrm{Asp}_{2}$ and $\mathrm{Asp}_{3}$ representing the global minima on the respective potentials of mean force on the flat (104) surface. We observe that the dominant mode of binding of aspartate to the flat surface is achieved through the zwitterionic pair, while the remaining carboxylate group stays solvated (Figure S8a). Same pattern can be observed for $\mathrm{Asp}_{2}$ and $\mathrm{Asp}_{3}$ as well (Figure S8b and Figure S8c), where the amino group is interacting with the carbonate in the crystal and there is an additional, albeit weaker, interaction through one of the carboxylate groups of the peptide.
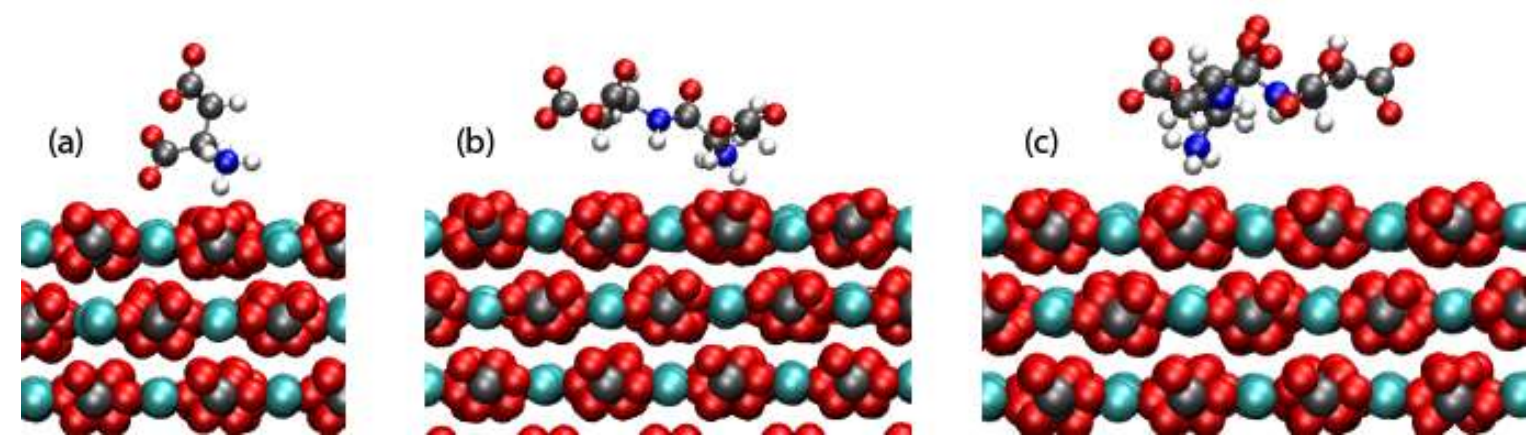

Figure S8. Dominant modes of binding of Asp, Asp, and Asp 3 to the (104) surface of calcite corresponding to the global minima on the PMFs shown in Figure S7. 
S10. Island Binding. For the analysis we used the eight lowest lying umbrella windows for each feature, effectively covering $3.2 \AA$ along the reaction coordinate. In those windows we calculated the distance of the COM of Asp, $\mathrm{Asp}_{2}$ and $\mathrm{Asp}_{3}$ from each individual feature. The collective data for all the features is then used to determine where the biomolecule spends the most time, and in the process the island feature(s) which contribute to the binding the most are identified. We used empirical binding cutoff values of $7 \AA, 8.5 \AA$ and $10 \AA$ for Asp, Asp $_{2}$ and $\mathrm{Asp}_{3}$, respectively. Those values were used because they are significantly larger than half of the distance from the N-terminal to C-terminal ends for individual biomolecules $(\sim 2.5 \AA$ for Asp, $\sim 4$ $\AA$ for $\mathrm{Asp}_{2}, \sim 5.5 \AA$ for $\mathrm{Asp}_{3}$ ). If the distance to all of the features exceeded this value, it is reasonable to consider the biomolecule not bound to the island. Otherwise, we said that the molecule is interacting with the closest island feature. Following this approach, we were able to classify the biomolecule in each frame to one of the seven classes: bound to acute carbonate, bound to obtuse carbonate, bound to acute edge, bound to obtuse edge, bound to calcium, bound to the middle of the island or unbound.
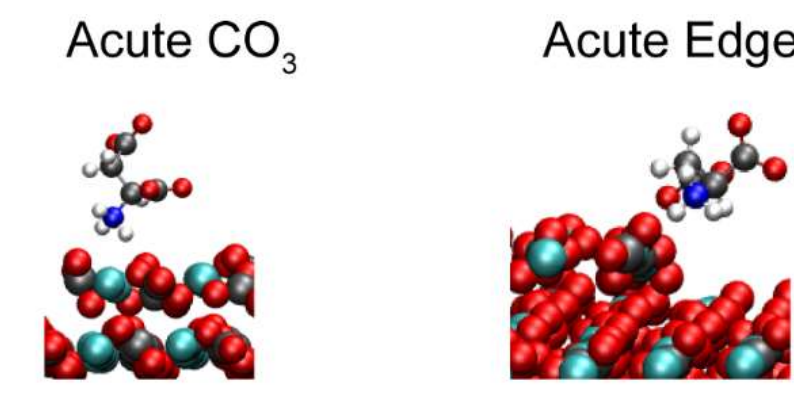

\section{Obtuse $\mathrm{CO}_{3}$}

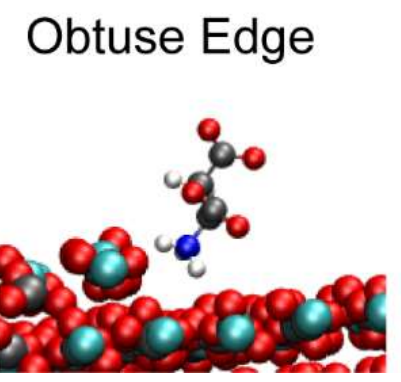

Calcium

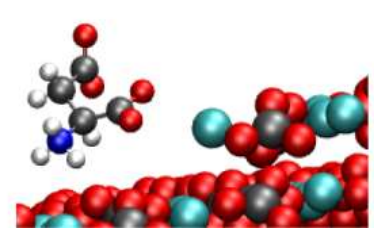

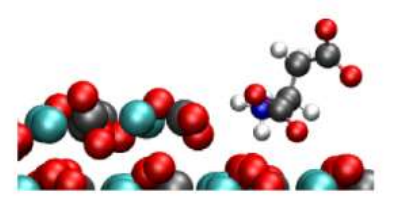

Middle

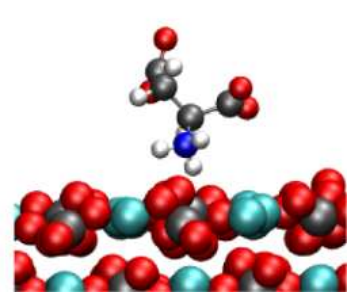

Figure S9. Most likely bound geometries of Asp to the specific features of the island, based on statistical analysis (Table S4). 


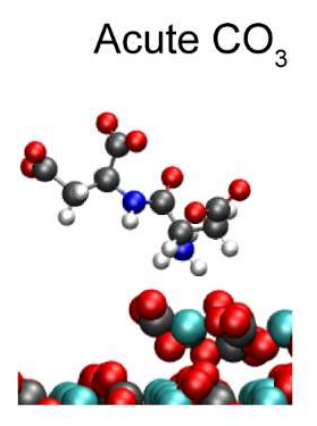

Obtuse Edge

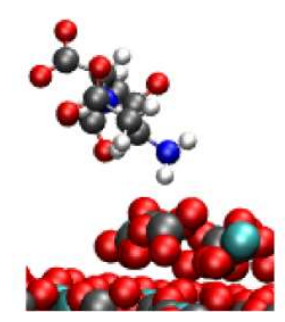

Acute Edge

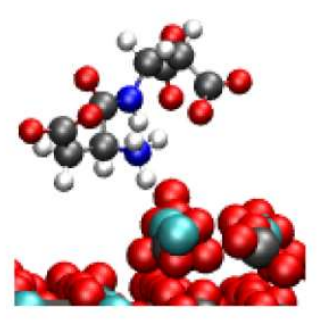

Calcium

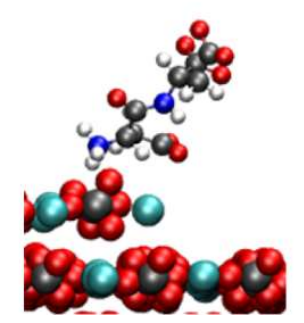

Obtuse $\mathrm{CO}_{3}$

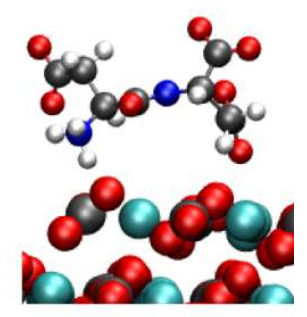

Middle

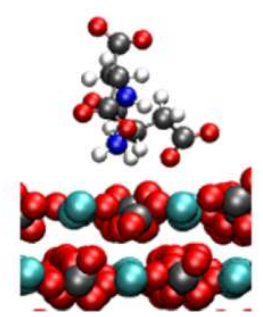

Figure S10. Most likely bound geometries of Asp 2 to the specific features of the island, based on statistical analysis (Table S5).

Acute $\mathrm{CO}_{3}$

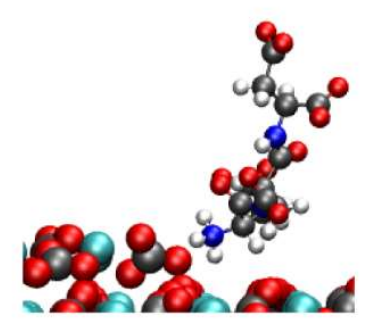

Obtuse Edge

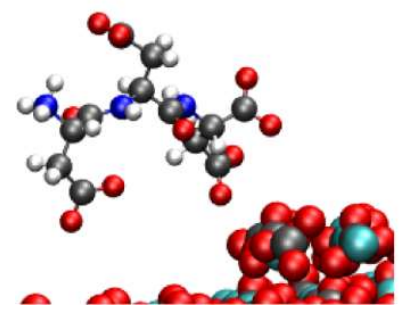

Acute Edge

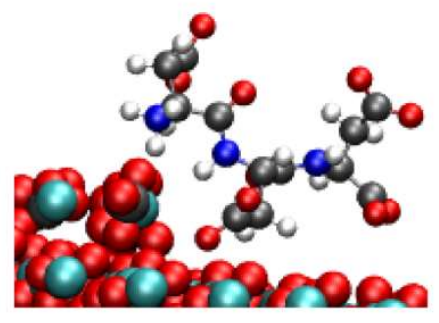

Calcium

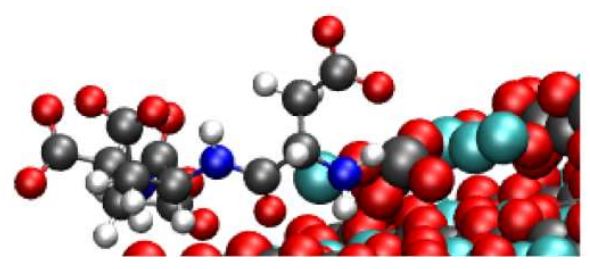

Obtuse $\mathrm{CO}_{3}$

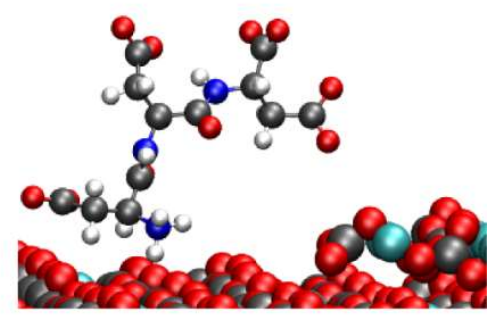

Middle

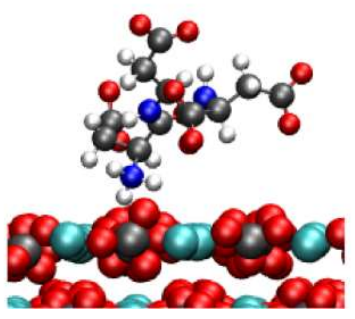

Figure S11. Most likely bound geometries of Asp 3 to the specific features of the island, based on statistical analysis (Table S6). 
Table S4. Average distance (nm) of Asp groups (nitrogen in the N-terminal amino group (ZN), carbon in the C-terminal carboxylic group (ZC), carbon in the carboxylate side chain (SC)) from the surface. Umbrella windows corresponding to the global minimum in the individual feature PMFs (not shown here) were used in the analysis, and the abbreviations used correspond to those found in Figure 4 in the main text.

\begin{tabular}{l|ccc}
\multicolumn{1}{l}{ FEATURES } & ZN & ZC & SC \\
\hline AC & $\mathbf{0 . 6 1}$ & 0.78 & 0.87 \\
AE & $\mathbf{0 . 5 3}$ & $\mathbf{0 . 5 3}$ & 0.70 \\
OC & $\mathbf{0 . 3 4}$ & $\mathbf{0 . 3 3}$ & 0.56 \\
OE & $\mathbf{0 . 3 5}$ & $\mathbf{0 . 4 8}$ & 0.71 \\
CA & $\mathbf{0 . 3 3}$ & 0.51 & 0.58 \\
MI & $\mathbf{0 . 6 1}$ & 0.76 & 0.80
\end{tabular}

Table S5. Average distance (nm) of Asp ${ }_{2}$ groups (nitrogen in the N-terminal amino group (ZN), carbon in the C-terminal carboxylic group (ZC), nitrogen forming the peptide bond (PN), carbon forming the peptide bond (PC), carbons in the carboxylate side chain (SC1 and SC2)) from the surface. Umbrella windows corresponding to the global minimum in the individual feature PMFs (not shown here) were used in the analysis, and the abbreviations used correspond to those found in Figure 4 in the main text.

\begin{tabular}{|l|cccccc}
\multicolumn{1}{l}{ FEATURE } & ZN & ZC & PN & PC & SC1 & SC2 \\
\hline AC & $\mathbf{0 . 6 0}$ & 1.04 & 0.84 & 0.79 & 0.81 & 0.97 \\
AE & $\mathbf{0 . 5 4}$ & 0.89 & 0.76 & $\mathbf{0 . 7 1}$ & $\mathbf{0 . 6 3}$ & 0.88 \\
OC & $\mathbf{0 . 6 2}$ & 0.94 & 0.79 & 0.76 & 0.79 & $\mathbf{0 . 7 0}$ \\
OE & $\mathbf{0 . 6 4}$ & 1.05 & 0.87 & 0.83 & 0.79 & 0.84 \\
CA & $\mathbf{0 . 6 2}$ & $\mathbf{0 . 7 4}$ & $\mathbf{0 . 7 2}$ & 0.77 & 0.77 & 0.87 \\
MI & $\mathbf{0 . 6 0}$ & 1.03 & 0.82 & 0.77 & $\mathbf{0 . 6 6}$ & 0.78
\end{tabular}

Table S6. Average distance (nm) of Asp 3 groups (nitrogen in the N-terminal amino group (ZN), carbon in the C-terminal carboxylic group, nitrogen forming the peptide bond (PN), carbon forming the peptide bond (PC), carbons in the carboxylate side chain (SC)) from the surface. Umbrella windows corresponding to the global minimum in the individual feature PMFs (not shown here) were used in the analysis, and the abbreviations used correspond to those found in Figure 4 in the main text.

\begin{tabular}{l|ccccccccc}
\multicolumn{1}{l}{ FEATURE } & ZN & ZC & PN1 & PC1 & PN2 & PC2 & SC1 & SC2 & SC3 \\
\hline AC & $\mathbf{0 . 3 2}$ & 0.83 & $\mathbf{0 . 4 8}$ & $\mathbf{0 . 4 8}$ & 0.71 & $\mathbf{0 . 6 3}$ & $\mathbf{0 . 5 4}$ & $\mathbf{0 . 5 7}$ & 0.91 \\
AE & $\mathbf{0 . 6 3}$ & $\mathbf{0 . 4 8}$ & $\mathbf{0 . 5 3}$ & 0.65 & $\mathbf{0 . 5 3}$ & $\mathbf{0 . 5 0}$ & 0.85 & $\mathbf{0 . 3 3}$ & 0.77 \\
OC & $\mathbf{0 . 3 3}$ & 0.95 & $\mathbf{0 . 6 2}$ & $\mathbf{0 . 5 4}$ & 0.82 & 0.76 & $\mathbf{0 . 5 0}$ & 0.95 & 0.78 \\
OE & 0.82 & 0.80 & 0.80 & 0.83 & 0.83 & 0.80 & $\mathbf{0 . 6 4}$ & 0.91 & 0.83 \\
CA & $\mathbf{0 . 3 2}$ & $\mathbf{0 . 5 1}$ & $\mathbf{0 . 4 2}$ & $\mathbf{0 . 3 5}$ & $\mathbf{0 . 3 9}$ & $\mathbf{0 . 4 6}$ & $\mathbf{0 . 6 1}$ & $\mathbf{0 . 5 4}$ & $\mathbf{0 . 3 2}$ \\
MI & $\mathbf{0 . 6 0}$ & 0.86 & 0.84 & 0.79 & 0.90 & 0.85 & 0.85 & 1.13 & 0.85
\end{tabular}




\section{S11. Binding Trends}

The dominant interaction of Asp derivatives with the calcite always involves binding through the positively charged $-\mathrm{NH}_{3}{ }^{+}$group to carbonate, and one of the closer - $\mathrm{COO}^{-}$groups to calcium. The side groups that do not interact are collected in the $-\mathrm{R}$ group that will vary in size across the aspartate derivatives series. As the length of the - $\mathrm{R}$ group increases the likelihood of additional COO- group binding also increases.

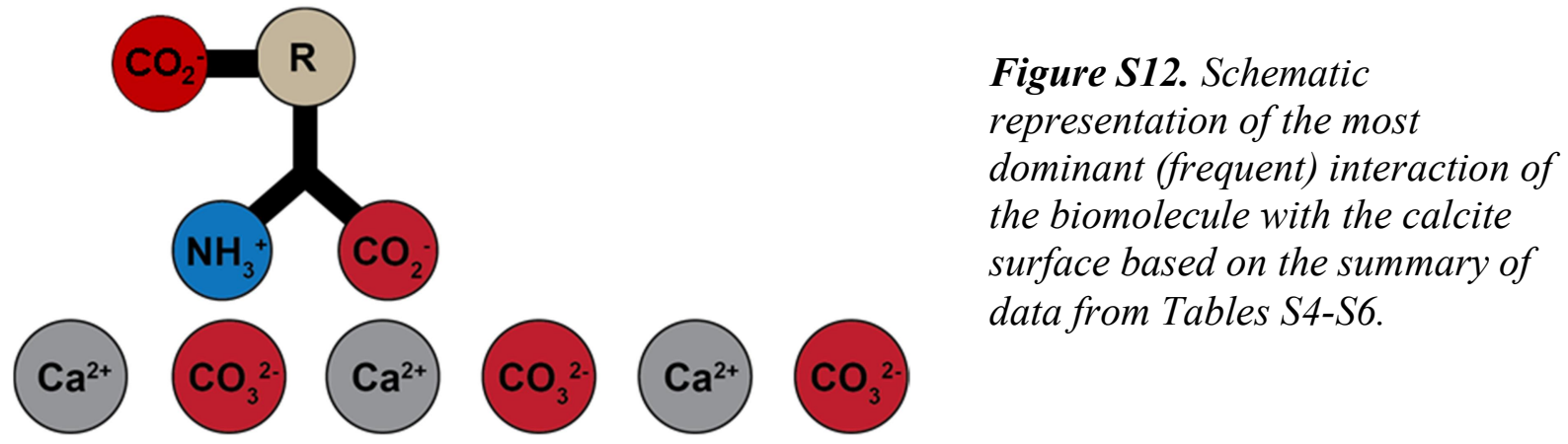

Last but not least, we compare the calculated binding energies (red dots) with previously reported mesurements (green and purple dots) and the here reported measurements (blue). Importantly, while the absolute values of binding energies may significantly differ, same trends are recovered in all of the data.

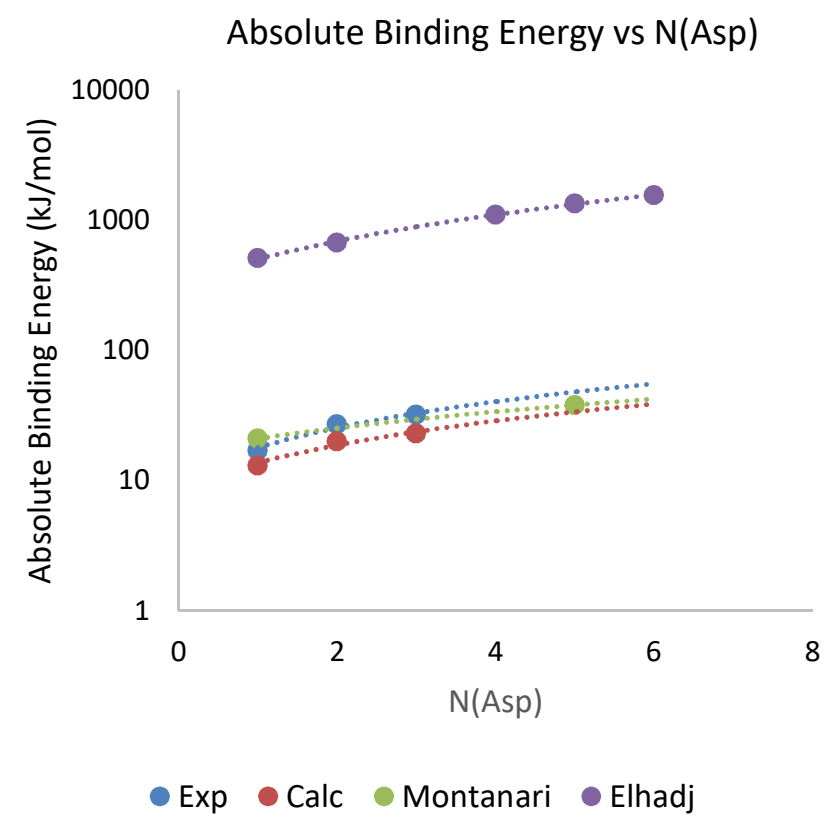

Figure S13. Comparison of the absolute binding energies from experimental measurements (Exp) and calculated values (Calc), in this work, with the previous measurements of Montanari et al. ${ }^{20}$ and the semi-empirical calculations of Elhadj et al. ${ }^{21}$ 


\section{S12. References}

1. Ukrainczyk, M.; Kontrec, J.; Babić-Ivančić, V.; Brečević, L.; Kralj, D. Experimental design approach to calcium carbonate precipitation in a semicontinuous process. Powder Technol. 2007, 171, 192-199.

2. Ukrainczyk, M.; Gredičak, M.; Jerić, I.; Kralj, D. Interactions of salicylic acid derivatives with calcite crystals. J. Colloid Interface Sci. 2012, 365, 296-307.

3. Ukrainczyk, M.; Gredičak, M.; Jerić, I.; Kralj, D. Interactions of Scalenohedral Calcite Crystals with Acidic Amino Acid Derivatives of Salicylic Acid. Cryst. Growth Des. 2014, 14, 4335-4346.

4. Wolthers, M.; Di Tommaso, D.; Du, Z.; de Leeuw, N. H. Calcite surface structure and reactivity: molecular dynamics simulations and macroscopic surface modelling of the calcite-water interface. Phys. Chem. Chem. Phys. 2012, 14, 15145-15157.

5. $\quad$ Pronk, S.; Páll, S.; Schulz, R.; Larsson, P.; Bjelkmar, P.; Apostolov, R.; Shirts, M. R.; Smith, J. C.; Kasson, P. M.; van der Spoel, D.; Hess, B.; Lindahl, E. GROMACS 4.5: a high-throughput and highly parallel open source molecular simulation toolkit.

Bioinformatics 2013, 29, 845-854.

6. Frisch, M. J.; Trucks, G. W.; Schlegel, H. B.; Scuseria, G. E.; Robb, M. A.; Cheeseman, J. R.; Scalmani, G.; Barone, V.; Petersson, G. A.; Nakatsuji, H.; Li, X.; Caricato, M.; Marenich, A.; Bloino, J.; Janesko, B. G.; Gomperts, R.; Mennucci, B.; Hratchian, H. P.; Ortiz, J. V.; Izmaylov, A. F.; Sonnenberg, J. L.; Williams-Young, D.; Ding, F.; Lipparini, F.; Egidi, F.; Goings, J.; Peng, B.; Petrone, A.; Henderson, T.; Ranasinghe, D.;

Zakrzewski, V. G.; Gao, J.; Rega, N.; Zheng, G.; Liang, W.; Hada, M.; Ehara, M.; Toyota, K.; Fukuda, R.; Hasegawa, J.; Ishida, M.; Nakajima, T.; Honda, Y.; Kitao, O.; Nakai, H.; Vreven, T.; Throssell, K.; Montgomery Jr., J. A.; Peralta, J. E.; Ogliaro, F.; Bearpark, M.; Heyd, J. J.; Brothers, E.; Kudin, K. N.; Staroverov, V. N.; Keith, T.; Kobayashi, R.; Normand, J.; Raghavachari, K.; Rendell, A.; Burant, J. C.; Iyengar, S. S.; Tomasi, J.; Cossi, M.; Millam, J. M.; Klene, M.; Adamo, C.; Cammi, R.; Ochterski, J. W.; Martin, R. L.; Morokuma, K.; Farkas, O.; Foresman, J. B.; Fox, D. J. Gaussian09, Revision A02, Gaussian, Inc.: Wallingford CT, 2016.

7. Case, D. A.; Betz, R. M.; Cerutti, D. S.; Cheatham, T. E.; Darden, T. A.; Duke, R. E.; Giese, T. J.; Gohlke, H.; Goetz, A. W.; Homeyer, N.; Izadi, S.; Janowski, P.; Kaus, J.; Kovalenko, A.; Lee, T. S.; LeGrand, S.; Li, P.; Lin, C.; Luchko, T.; Luo, R.; Madej, B.; Mermelstein, D.; Merz, K. M.; Monard, G.; Nguyen, H.; Nguyen, H. T.; Omelyan, I.; Onufriev, A.; Roe, D. R.; Roitberg, A.; Sagui, C.; Simmerling, C. L.; Botello-Smith, W. M.; Swails, J.; Walker, R. C.; Wang, J.; Wolf, R. M.; Wu, X.; Xiao, L.; Kollman, P. A. $A M B E R$ 2016, University of California: San Francisco, 2016.

8. Gale, J. D.; Rohl, A. L. The General Utility Lattice Program ( GULP ). Mol. Simul. 2003, 29, 291-341.

9. Humphrey, W.; Dalke, A.; Schulten, K. VMD: Visual molecular dynamics. J. Mol. Graph. 1996, 14, 33-38.

10. Darden, T.; York, D.; Pedersen, L. Particle mesh Ewald: An N·log(N) method for Ewald sums in large systems. J. Chem. Phys. 1993, 98, 10089.

11. Essmann, U.; Perera, L.; Berkowitz, M. L.; Darden, T.; Lee, H.; Pedersen, L. G. A smooth particle mesh Ewald method. J. Chem. Phys. 1995, 103, 8577. 
12. Hub, J. S.; de Groot, B. L.; van der Spoel, D. g_wham_-A Free Weighted Histogram Analysis Implementation Including Robust Error and Autocorrelation Estimates. J. Chem. Theory Comput. 2010, 6, 3713-3720.

13. Raiteri, P.; Demichelis, R.; Gale, J. D.; Kellermeier, M.; Gebauer, D.; Quigley, D.; Wright, L. B.; Walsh, T. R. Exploring the influence of organic species on pre- and post-nucleation calcium carbonate. Faraday Discuss. 2012, 159, 61-85.

14. Raiteri, P.; Gale, J. D.; Quigley, D.; Rodger, P. M. Derivation of an Accurate Force-Field for Simulating the Growth of Calcium Carbonate from Aqueous Solution: A New Model for the Calcite-Water Interface. J. Phys. Chem. C 2010, 114, 5997-6010.

15. Jorgensen, W. L.; Chandrasekhar, J.; Madura, J. D.; Impey, R. W.; Klein, M. L. Comparison of simple potential functions for simulating liquid water. J. Chem. Phys. 1983, 79, 926-935.

16. Best, R. B.; Hummer, G. Optimized molecular dynamics force fields applied to the helixcoil transition of polypeptides. J. Phys. Chem. B 2009, 113, 9004-9015.

17. Schröder, K.-P.; Sauer, J.; Leslie, M.; Richard, C.; Catlow, A.; Thomas, J. M. Bridging hydrodyl groups in zeolitic catalysts: a computer simulation of their structure, vibrational properties and acidity in protonated faujasites (HxY zeolites). Chem. Phys. Lett. 1992, 188, 320-325.

18. Freeman, C. L.; Harding, J. H.; Cooke, D. J.; Elliott, J. A.; Lardge, J. S.; Duffy, D. M. New forcefields for modeling biomineralization processes. J. Phys. Chem. C 2007, 111, $11943-$ 11951.

19. Møller, C.; Plesset, M. S. Note on an Approximation Treatment for Many-Electron Systems. Phys. Rev. 1934, 46, 618-622.

20. Montanari, G.; Lakshtanov, L. Z.; Tobler, D. J.; Dideriksen, K.; Dalby, K. N.; Bovet, N.; Stipp, S. L. S. Effect of Aspartic Acid and Glycine on Calcite Growth. Cryst. Growth Des. 2016, 16, 4813-4821.

21. Elhadj, S.; Salter, E. A.; Wierzbicki, A.; De Yoreo, J. J.; Han, N.; Dove, P. M. Peptide Controls on Calcite Mineralization: Polyaspartate Chain Length Affects Growth Kinetics and Acts as a Stereochemical Switch on Morphology. Cryst. Growth Des. 2005, 6, 197 201. 